\title{
Developing a Model for Chloride Ions Transport in Cement Concrete under Dynamic Flexural Loading and Dry-Wet Cycles
}

\author{
Bo-wen Guan, ${ }^{1}$ Jia-yu Wu, ${ }^{1}$ Tao Yang, ${ }^{2}$ An-hua Xu, ${ }^{3}$ Yan-ping Sheng, ${ }^{1}$ and Hua-xin Chen ${ }^{1}$ \\ ${ }^{1}$ School of Materials Science \& Engineering, Chang'an University, Xi'an, Shaanxi 710061, China \\ ${ }^{2}$ School of Transportation, Southeast University, Nanjing, Jiangsu 210096, China \\ ${ }^{3}$ Qinghai Research Institute of Transportation, Qinghai 810008, China
}

Correspondence should be addressed to Hua-xin Chen; hxchen@chd.edu.cn

Received 23 August 2017; Revised 5 November 2017; Accepted 28 November 2017; Published 24 December 2017

Academic Editor: Alessandro Arsie

Copyright (C) 2017 Bo-wen Guan et al. This is an open access article distributed under the Creative Commons Attribution License, which permits unrestricted use, distribution, and reproduction in any medium, provided the original work is properly cited.

\begin{abstract}
Chloride ions attack is the main factor leading to the degradation of concrete durability, while the diffusion process would be significantly aggravated under the dynamic flexural loading and dry-wet cycles. In this paper, the influence coefficients of dynamic flexural loading on chloride/water diffusion coefficients were established, based on the relationship between the dynamic flexural loading and the chloride ions diffusion coefficient of concrete. Based on the model of chloride ions transporting in dry-wet cycle environment, the transport model of chloride ions in concrete under the dynamic flexural loading and dry-wet cycles was established. The effects of different factors on the chloride ions transport law in concrete were analyzed through laboratory test. The results showed that the model was in good agreement with the experimental results. The theory and assumptions proposed applied in the model of chloride ions transport in concrete under the dynamic flexural loading and dry-wet cycles had certain rationality and scientificity.
\end{abstract}

\section{Introduction}

Chloride ions could greatly harm the durability of reinforced concrete structures. In the area rich in chloride salt, concrete structures are not only exposed to chloride environment, but also subjected to the fatigue failure caused by repeated traffic loads. Under the dynamic flexural loading, the microcracks of concrete could easily sprout and expand. These microcracks not only constitute the transport channel of chloride ions, but also contribute to the water diffusion in concrete which increases the driving force of diffusion and convection. As for the concrete structure in tidal region, or areas where splash and water level change is prevailing, the concrete also suffers from dry-wet cycle of chloride solution. When concrete is in unsaturated state, the transmission of chloride ions in concrete is faster [1]. Due to the defect of design standard, the durability of concrete is insufficient. The cost of maintenance is increasing continuously which causes huge economic loss $[2,3]$. Therefore, studying the effect of dynamic flexural loading and dry-wet cycles on chloride ions diffusion in concrete is of great significance for ensuring the safe operation of concrete works in the chloride enrichment area, and accurately predicting and improving the service life of the project. Chloride ions diffusion process in concrete has been studied by several researchers. Many of them [4-7] study the chloride diffusion characteristic in concrete based on Fick's second law. The influences of different fatigue stress levels and temperature coupling on the chloride diffusion coefficient of concrete were investigated by Wang et al. $[8,9]$. Ren et al. [10] had found that the chloride ions permeability coefficient and the fatigue stress level have an exponential relationship under the combined effect of fatigue load and chloride solution immersion. The combined action of loads with a chloride dry-wet cycle and freeze-thaw cycle on the flexural performance of reinforced concrete (RC) beams strengthened with textile reinforced concrete was studied by Yin et al. [11]. It had been found that the coupling of load and chloride ions caused sustained damage to the textile reinforced concrete (TRC) and reduced the durability of the TRC. The chloride penetration process in concrete with two different replacement ratios by supplementary cementitious materials, three different levels of flexural loading, and 
three different types of drying-wetting-carbonation exposure conditions was experimentally characterized by Ye et al. [12]. The result showed that the incorporation of supplementary cementitious materials makes concrete more vulnerable to chloride attack under a combined deterioration of cyclic drying-wetting and carbonation, since the deficiency of portlandite dominates the positive effects such as pore refinement. At present, the transmission model of chloride ions in concrete under different environmental factors or mechanical properties has been addressed by many researchers [13-16]. But little information is available about the experimental and theoretical analysis of chloride ions transport in concrete under the combined action of dynamic flexural loading and dry-wet cycle.

In this paper, transport behavior of chloride ions under the combined action of dynamic flexural loading and drywet cycles is considered as the effect of dynamic flexural loading on the chloride ions diffusion coefficient and water diffusion coefficient. The influence coefficients of dynamic flexural loading on chloride ions diffusion coefficient and water diffusion coefficient were established, respectively. And then according to the equation of chloride ions transport in concrete under the action of dry-wet cycle and the equation of chloride ions transport in concrete under the action of dynamic flexural loading, the equation of chloride ions transport in concrete under the combined action of dynamic flexural loading and dry-wet cycles was established. The rationality of the model was verified by comparing the experimental results and model results. The research results provide a reference for the design and life prediction of road concrete engineering under the interaction of dynamic flexural loading and dry-wet cycle in a salt rich environment.

\section{Model for Chloride Ions Transport in Cement Concrete under Dynamic Flexural Loading}

\subsection{Characterization of Chloride Ions Diffusion Coefficient} Based on Crack Area. In concrete, there are native microcracks and connected micropores. When concrete is subjected to chloride attack, the chloride ions will pass through the pores and defects into the concrete and spread to the depth. The dynamic flexural loading intensifies the initiation and propagation of microcracks in concrete. And the chloride ions diffusion channel and diffusion rate increase consequently. When dynamic flexural loading is applied to concrete, the microcracks in concrete would open, and the tip of the crack could generate a partial vacuum, resulting in the chloride solution entering the crack rapidly by pumping. When the load is unloaded, the closed crack would force salt solution spraying. In such a cycle, the chloride solution forms turbulent diffusion near the microcracks, which greatly improves the diffusion capacity of chloride ions.

Here, the concrete is divided into two parts: the matrix and the microcrack. The chloride ions diffuse into the concrete through the pores and microcracks of the matrix. The total diffusion flux of chloride ions into the concrete includes the matrix diffusion flux and microcrack diffusion flux, as shown below:

$$
J\left(A_{m}+A_{c}\right)=J_{m} A_{m}+J_{c} A_{c},
$$

where $J$ is the total chloride ions diffusion flux into the concrete; $J_{m}$ is the chloride ions diffusion flux into concrete through the matrix; $J_{c}$ is the chloride ions diffusion flux into the concrete through the crack; $A_{m}$ is the area of the concrete matrix; $A_{c}$ is the area of concrete cracks.

According to the diffusion theory, diffusion flux is the product of the diffusion coefficient of ions by the ion concentration gradient, as follows:

$$
\begin{gathered}
J=-D \frac{\partial \rho_{c}}{\partial X}, \\
J_{m}=-D_{m} \frac{\partial \rho_{c}}{\partial X}, \\
J_{c}=-D_{c} \frac{\partial \rho_{c}}{\partial X},
\end{gathered}
$$

where $\rho_{c}$ is the mass concentration of chloride ions; $X$ is the diffusion direction of chloride ions; $D$ is the total diffusion coefficient of chloride ions in concrete; $D_{m}$ is diffusion coefficient of chloride ions through concrete matrix; $D_{c}$ is diffusion coefficients of chloride ions through cracks.

Then (2) are taken into (1) and deformed:

$$
D=\frac{D_{m} A_{m}+D_{c} A_{c}}{A_{m}+A_{c}} .
$$

Equation (3) is the diffusion coefficient of chloride ions characterized by the crack area. The chloride diffusion coefficient is the result of the integration of chloride ions diffusing through the connected pore and crack. It is an equivalent diffusion coefficient and it can be tested according to the Nordic standard NT BUILD 443-The immersion test.

For ordinary concrete, the crack area is very small and the matrix area is much larger than the crack area, so (3) can be simplified as

$$
D=D_{m}+\frac{A_{c}}{A_{m}} D_{c} .
$$

If the dynamic flexural loading is applied to the concrete, the dynamic flexural loading will cause the fatigue cumulative damage to the concrete. The crack area will increase and the chloride ions diffusion coefficient will also increase. The chloride ions diffusion coefficient can be expressed as below after the damage:

$$
D^{\prime}=D_{m}+\frac{A_{c}^{\prime}}{A_{m}} D_{c},
$$

where $D^{\prime}$ is the chloride diffusion coefficient after fatigue damage of concrete; $A_{c}^{\prime}$ is the crack area of concrete after fatigue damage.

The crack area consists of two parts, the initial crack area and the extended crack area:

$$
A_{c}^{\prime}=A_{c}+\Delta A_{c},
$$




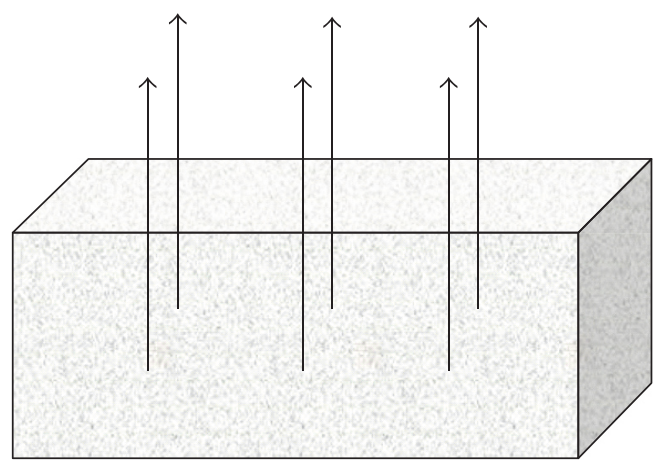

FIGURE 1: One-dimensional diffusion of chloride ions in concrete.

where $\Delta A_{c}$ is the change of crack area of the concrete after fatigue damage.

Then (6) is taken into (5), obtaining

$$
D^{\prime}=D_{m}+\frac{A_{c}}{A_{m}} D_{c}+\frac{\Delta A_{c}}{A_{m}} D_{c}=D+\frac{\Delta A_{c}}{A_{m}} D_{c},
$$

where $D$ is the equivalent chloride ions diffusion coefficient tested according to the Nordic standard NT BUILD 443The immersion test or other methods; $D_{c}$ is the maximum diffusion coefficient of chloride ions in concrete cracks.

Equation (7) is the characterization of chloride ions diffusion coefficient based on crack area and initial diffusion coefficient after the fatigue damage.

2.2. Effects of Fatigue Damage on Crack Area. The bottom of middle part of concrete beam and pavement slab is under the maximum flexural tensile stress. Under the combined action of cyclic bending stress and chloride diffusion, the bending deformation of this part is the largest and the structure is the weakest. It will lead to the fastest rate of chloride ions penetration. A unit is selected from this part as shown in Figure 1. Three hypotheses are made as follows:

(1) The concrete is homogeneous and the chloride ions diffuse in the concrete unit in one dimension;

(2) The initial microcracks are evenly distributed in the concrete;

(3) The damage of concrete is only the expansion of microcracks during fatigue damage.

On the basis of the above assumptions, the following three steps can be done as shown in Figure 2:

(1) An interface perpendicular to the direction of diffusion is selected. Microcracks in this interface are evenly distributed.

(2) This interface is evenly divided into $N$ microarea units, so that each microarea unit contains a microcrack.

(3) The irregular crack in the microarea unit is simplified into a rectangle so that the area of the rectangle can be equal to the initial crack area.

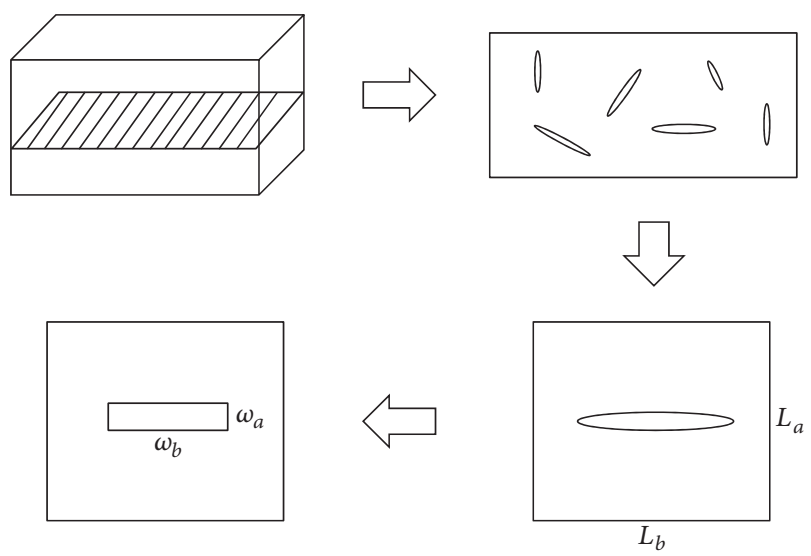

FIGURE 2: Equivalent simplification of concrete microcrack.

According to the equivalent simplification shown in Figure 2 of the crack area, the length and width of the simplified rectangle are $\omega_{b}, \omega_{a}$, respectively. The initial crack area is

$$
A_{c}=N \omega_{a} \omega_{b},
$$

where $N$ is the number of microarea units to be divided.

After fatigue damage occurs, the growth of microcracks is the growth of crack length and crack width. After expansion, the length and width of cracks are

$$
\begin{aligned}
& \omega_{b}^{\prime}=\frac{\omega_{b}}{1-d}, \\
& \omega_{a}^{\prime}=\frac{\omega_{a}}{1-d},
\end{aligned}
$$

where $d$ is the fatigue cumulative damage of the concrete.

Then, after the damage, the crack area in the concrete is

$$
A_{c}^{\prime}=N \omega_{a}^{\prime} \omega_{b}^{\prime}=\frac{N \omega_{a} \omega_{b}}{(1-d)^{2}} .
$$

The change of the crack area is

$$
\begin{aligned}
\Delta A_{c} & =A_{c}^{\prime}-A_{c}=N \omega_{a} \omega_{b}\left[\frac{1}{(1-d)^{2}}-1\right] \\
& =A_{c}\left[\frac{1}{(1-d)^{2}}-1\right] .
\end{aligned}
$$

Equation (11) is taken into (7), obtaining

$$
D^{\prime}=D+D_{c} \frac{A_{c}}{A_{m}}\left[\frac{1}{(1-d)^{2}}-1\right] .
$$

Making $\rho_{e}=A_{c} / A_{m}=$ Initial microcrack area/matrix area, then (12) can be converted into

$$
D^{\prime}=D+D_{c} \rho_{e}\left[\frac{1}{(1-d)^{2}}-1\right] .
$$


It can be seen from the definition of $\rho_{e}$ that it represents the initial microcrack density of the concrete. The vacuum epoxy dipping method and the fluorescent liquid displacement method can be used to measure the initial microcrack density of the concrete $[17,18]$. It can be seen from (13) that the chloride ions diffusion coefficient of fatigue-damaged concrete can be expressed by the initial microcrack area density and fatigue cumulative damage.

2.3. Introduction of Dynamic Flexural Loading. Dynamic flexural loading causes damage to concrete. Fatigue damage accumulates with the number of loading times increasing. According to the linear fatigue cumulative damage theory [19], the fatigue damage of concrete is proportional to the number of loading times:

$$
d=\frac{n}{N_{f}}
$$

where $n$ is the time of dynamic flexural loading; $N_{f}$ is fatigue life of concrete.

The time of dynamic flexural loading $n$ is the product of the load frequency and load times:

$$
n=f t
$$

where $f$ is the frequency of the dynamic flexural loading; $t$ is times of action of dynamic flexural loading.

According to the fatigue equation of concrete [20], the fatigue life of concrete has a semilogarithmic relationship with the maximum stress:

$$
S=a-b \lg N_{f}
$$

where $S$ is the maximum stress level under dynamic flexural loading; $a, b$ are test constants related to materials.

Equations (15) and (16) are taken into (14), and then (17) is available:

$$
d=\frac{f t}{10^{(a-S) / b}} .
$$

Equation (17) is taken into (13), and then (18) is available:

$$
D^{\prime}=D+D_{c} \rho_{e}\left[\frac{1}{\left(1-f t / 10^{(a-S) / b}\right)^{2}}-1\right] .
$$

Equation (18) is the expression of the influence of dynamic flexural loading on chloride diffusion coefficient of concrete. The influence of stress level, frequency, and the action time of dynamic flexural loading on the diffusion coefficient of chloride ions can be analyzed quantitatively.

\section{Model for Chloride Ions Transport in Cement Concrete under Dry-Wet Cycles}

The flux of chloride ions into the concrete under dry-wet cycle is mainly divided into two parts which are diffusion flux and convection flux, respectively:

$$
J=J_{d}+J_{c},
$$

where $J_{d}$ is the diffusion flux; $J_{c}$ is the convection flux.
Chloride diffusion flux can be expressed by Fick's first law as shown in (20):

$$
J=-\Theta D \operatorname{grad} C_{p}
$$

where the negative sign indicates that the chloride ions diffusion is opposite to the concentration gradient; $\Theta$ is the water content of concrete, $\%$; $D$ is the chloride ions diffusion coefficient, $\mathrm{m}^{2} / \mathrm{s} ; C_{p}$ is the chloride concentration in the pore liquid, $\mathrm{kg} / \mathrm{m}^{3}$.

The chloride ions diffusion coefficient $D$ is related to concrete age, chloride ions adsorption effect, ambient temperature, and concrete saturation. The chloride ions diffusion coefficient decreases exponentially with the age of concrete [21]:

$$
D_{t}=D_{\text {ref }}\left(\frac{t_{\text {ref }}}{t}\right)^{m}
$$

where $D_{t}$ is the chloride ions diffusion coefficient at time $t$; $D_{\text {ref }}$ is the chloride ions diffusion coefficient at age $t_{\text {ref }}$, generally taking $28 \mathrm{~d} ; m$ is the time attenuation coefficient, which could be 0.65 for ordinary Portland cement in the marine environment; tide and splash area is 0.37 and underwater area is 0.30 [22].

As for concrete which has a greater saturation, the diffusion of the chloride ions could be accelerated in a higher manner. Guimarães et al. [23, 24] found that the chloride diffusion coefficient had a good correlation with the quadratic function of concrete saturation:

$$
D_{s}=D_{0}\left(a_{0} s+b_{0} s+c_{0}\right)
$$

where $D_{s}$ is the diffusion coefficient of saturation $s ; D_{0}$ is the chloride ions diffusion coefficient in saturated state; $a, b$, and $c$ are fitting constants.

The higher the temperature is, the greater the diffusion coefficient of chloride ions would be. The relationship between temperature and the chloride ions diffusion coefficient is [25]

$$
D_{T}=D_{T_{0}} e^{\left(E_{a} / R\right)\left(1 / T_{0}-1 / T\right)}
$$

where $D_{T_{0}}$ is the chloride ions diffusion coefficient at temperature $T_{0} ; T_{0}$ usually takes $293 \mathrm{~K} ; R$ is gas constant; $E_{a}$ is activation energy of chloride diffusion in concrete, $\mathrm{J} / \mathrm{mol}$. When water cement ratio is $0.4, E_{a}$ is $41800 \mathrm{~J} / \mathrm{mol}$. When water cement ratio is $0.5, E_{a}$ is $44600 \mathrm{~J} / \mathrm{mol}$. When water cement ratio is $0.6, E_{a}$ is $32000 \mathrm{~J} / \mathrm{mol}$.

Based on the (21), (22), and (23), considering the effect of the age of concrete, environment temperature and concrete saturation on the chloride diffusion coefficient, chloride ions diffusion coefficient $D$ is

$$
D=D_{r, 0}^{T_{0}}\left(\frac{t_{r}}{t}\right)^{m} e^{(E / R)\left(1 / T_{0}-1 / T\right)}\left(a_{0} s^{2}+b_{0} s+c_{0}\right),
$$

where $D_{r, 0}^{T_{0}}$ is chloride ions diffusion coefficient at temperature $T_{0}, 28 \mathrm{~d}$ age, and saturated state. It can be measured 
according to the Nordic standard NT BUILD 443-The immersion test.

Thus, the chloride diffusion flux into the concrete can be expressed as

$$
\begin{aligned}
J_{d}= & -\Theta D_{r, 0}^{T_{0}}\left(\frac{t_{r}}{t}\right)^{m} e^{(E / R)\left(1 / T_{0}-1 / T\right)}\left(a_{0} s^{2}+b_{0} s+c_{0}\right) \\
& \cdot \operatorname{grad} C_{p} .
\end{aligned}
$$

The chloride ions flux caused by convection is

$$
J_{c}=C_{p} v
$$

where, $v$ is the velocity of water seepage, $\mathrm{m} / \mathrm{s}$.

The velocity of water seepage in concrete accords with Darcy's law:

$$
v=-\frac{k}{\eta} \frac{d p}{d x}=-\frac{k}{\eta} \frac{\partial p}{\partial \Theta} \cdot \frac{\partial \Theta}{\partial x}
$$

where, $k$ is seepage coefficient, $\mathrm{m} / \mathrm{s}[26] ; \eta$ is the viscous coefficient of pore fluid, Pa.s; $p$ is pressure head, $m$.
Making $D_{\mathrm{H}_{2} \mathrm{O}}(\Theta)=-(k / \eta)(\partial p / \partial \Theta),(27)$ can be expressed as

$$
v=-D_{\mathrm{H}_{2} \mathrm{O}}(\Theta) \frac{\partial \Theta}{\partial x}=-D_{\mathrm{H}_{2} \mathrm{O}}(\Theta) \operatorname{grad} \Theta
$$

$D_{\mathrm{H}_{2} \mathrm{O}}(\Theta)$ is water diffusion coefficient in concrete. It is a function of water content in concrete. Water content in concrete is related to porosity and saturation of concrete. Therefore, water diffusion coefficient is a function of porosity and saturation of concrete. It is assumed that the porosity of concrete is a time-irrelevant constant, so

$$
D_{\mathrm{H}_{2} \mathrm{O}}(\Theta)=D_{\mathrm{H}_{2} \mathrm{O}}(s) \text {. }
$$

In dry-wet cycle process, the diffusion coefficient of water is different at different stages of wetting and drying:

$$
D_{\mathrm{H}_{2} \mathrm{O}}(s)= \begin{cases}D_{\mathrm{H}_{2} \mathrm{O}}^{d}(s) & \text { Drying process } \\ D_{\mathrm{H}_{2} \mathrm{O}}^{w}(s) & \text { Wetting process. }\end{cases}
$$

Lin et al. [27] considered the influence of concrete age, saturation, and temperature on water diffusion coefficient and established the relationship between water diffusion coefficient and the three factors:

$$
D_{\mathrm{H}_{2} \mathrm{O}}(s)= \begin{cases}D^{d} e^{(U / R)\left(1 / T_{0}-1 / T\right)}\left(0.3+\sqrt{\frac{13}{t}}\right)\left[\alpha+\frac{1-\alpha}{1+\left((1-s) /\left(1-s_{c}\right)\right)^{N}}\right] & \text { Drying process } \\ D^{w} e^{(U / R)\left(1 / T_{0}-1 / T\right)}\left(0.3+\sqrt{\frac{13}{t}}\right) e^{n s} & \text { Wetting process, }\end{cases}
$$

where $D^{d}$ is the water diffusion coefficient in concrete when saturation is $1 ; D^{w}$ is water diffusion coefficient in concrete at initial saturation; $U$ is transport activation energy of water in concrete, $\mathrm{kJ} / \mathrm{mol} ; \alpha, s_{c}, N$ are constant $\left(\alpha=0.05, s_{c}=0.792\right.$, $N=6) ; n$ is constant, $n=6$.

Here, considering the influence of concrete age, saturation, and environment temperature on the diffusion of water in concrete, the convection flux of chloride ions in concrete can be expressed as

$$
J_{c}=-C_{p} D_{\mathrm{H}_{2} \mathrm{O}}(s) \operatorname{grad} \Theta .
$$

Equations (25) and (32) are taken into (19), and then chloride flux entering concrete through diffusion and convection under dry-wet cycle is

$$
\begin{aligned}
J= & -\Theta D_{r, 0}^{T_{0}}\left(\frac{t_{r}}{t}\right)^{m} e^{(E / R)\left(1 / T_{0}-1 / T\right)}\left(a_{0} s^{2}+b_{0} s+c_{0}\right) \\
& \cdot \operatorname{grad} C_{p}-C_{p} D_{\mathrm{H}_{2} \mathrm{O}}(s) \operatorname{grad} \Theta .
\end{aligned}
$$

According to the conservation of total mass of chloride ions:

$$
\frac{\partial\left(\Theta C_{p}\right)}{\partial t}=-\frac{\partial J}{\partial x} .
$$

Equation (33) is taken into (34):

$$
\begin{aligned}
& \frac{\partial\left(\Theta C_{p}\right)}{\partial t}=\frac{\partial}{\partial x}\left[\Theta D_{r, 0}^{T_{0}}\left(\frac{t_{r}}{t}\right)^{m}\right. \\
& \cdot e^{(E / R)\left(1 / T_{0}-1 / T\right)}\left(a_{0} s^{2}+b_{0} s+c_{0}\right) \operatorname{grad} C_{p} \\
& \left.\quad+C_{p} D_{\mathrm{H}_{2} \mathrm{O}}(s) \operatorname{grad} \Theta\right] .
\end{aligned}
$$

Water content of concrete can be expressed as

$$
\Theta=\varphi s,
$$

where $\varphi$ is the porosity of concrete, $\%$.

Equation (36) is taken into (35) available:

$$
\begin{aligned}
& \frac{\partial\left(\varphi s C_{p}\right)}{\partial t}=\frac{\partial}{\partial x}\left[\varphi s D_{r, 0}^{T_{0}}\left(\frac{t_{r}}{t}\right)^{m}\right. \\
& \cdot e^{(E / R)\left(1 / T_{0}-1 / T\right)}\left(a_{0} s^{2}+b_{0} s+c_{0}\right) \operatorname{grad} C_{p} \\
& \left.+C_{p} D_{\mathrm{H}_{2} \mathrm{O}}(s) \operatorname{grad}(\varphi s)\right] .
\end{aligned}
$$

Because chloride ions can only transport through the pores inside the concrete and the chloride concentration 
in the pores is difficult to measure, so the chloride ions concentration in pores is converted to the concentration where chloride ion occupies the mass of concrete ratio $C^{\prime}, \%$.

$$
C_{p}=\frac{C^{\prime} \rho_{c}}{\varphi s}
$$

where $\rho_{c}$ is the density of concrete, $\mathrm{kg} / \mathrm{m}^{3}$.

Equation (38) is taken into (37):

$$
\begin{aligned}
& \frac{\partial\left(C^{\prime}\right)}{\partial t}=\frac{\partial}{\partial x}\left[\varphi s D_{r, 0}^{T_{0}}\left(\frac{t_{r}}{t}\right)^{m}\right. \\
& \cdot e^{(E / R)\left(1 / T_{0}-1 / T\right)}\left(a_{0} s^{2}+b_{0} s+c_{0}\right) \operatorname{grad} \frac{C^{\prime}}{\varphi s}+\frac{C^{\prime}}{\varphi s} \\
& \left.\cdot D_{\mathrm{H}_{2} \mathrm{O}}(s) \operatorname{grad}(\varphi s)\right] .
\end{aligned}
$$

The porosity of concrete decreases with the increase of concrete age. The effect of concrete age on chloride diffusion coefficient and water diffusion coefficient is considered. So the change of porosity with time and space is neglected in (40) for

$$
\begin{aligned}
& \frac{\partial C^{\prime}}{\partial t}=\frac{\partial}{\partial x}\left[D_{r, 0}^{T_{0}}\left(\frac{t_{r}}{t}\right)^{m}\right. \\
& \cdot e^{(E / R)\left(1 / T_{0}-1 / T\right)}\left(a_{0} s^{2}+b_{0} s+c_{0}\right) \operatorname{grad} C^{\prime}+\frac{C^{\prime}}{s} \\
& \left.\cdot D_{\mathrm{H}_{2} \mathrm{O}}(s) \operatorname{grad}(s)\right] .
\end{aligned}
$$

When the binding of chloride ions was considered, the left side of (40) is the change of the total chloride ions concentration with time, and the right side is the free chloride ions flux; then (40) can be transformed into

$$
\begin{aligned}
& \frac{\partial C_{t}}{\partial t}=\frac{\partial}{\partial x}\left[D_{r, 0}^{T_{0}}\left(\frac{t_{r}}{t}\right)^{m}\right. \\
& \cdot e^{(E / R)\left(1 / T_{0}-1 / T\right)}\left(a_{0} s^{2}+b_{0} s+c_{0}\right) \operatorname{grad} C_{f}+\frac{C_{f}}{s} \\
& \left.\cdot D_{\mathrm{H}_{2} \mathrm{O}}(s) \operatorname{grad}(s)\right] .
\end{aligned}
$$

And the total concentration of chloride ions entering the concrete is the sum of free chloride ions concentration and combined chloride ions concentration as

$$
C_{t}=C_{b}+C_{f}
$$

where $C_{t}$ is the total concentration of chloride ions, $\%$; $C_{b}$ is combined chloride ions concentration, $\% ; C_{f}$ is free chloride ions concentration, $\%$.
The left side of (41) is changed as

$$
\begin{aligned}
\frac{\partial C_{t}}{\partial t} & =\frac{\partial C_{t}}{\partial C_{f}} \frac{\partial C_{f}}{\partial t}=\frac{\partial\left(C_{b}+C_{f}\right)}{\partial C_{f}} \frac{\partial C_{f}}{\partial t} \\
& =\left(1+\frac{\partial C_{b}}{\partial C_{f}}\right) \frac{\partial C_{f}}{\partial t} .
\end{aligned}
$$

Then (44) is available:

$$
\begin{aligned}
& \left(1+\frac{\partial C_{b}}{\partial C_{f}}\right) \frac{\partial C_{f}}{\partial t}=\frac{\partial}{\partial x}\left[D_{r, 0}^{T_{0}}\left(\frac{t_{r}}{t}\right)^{m}\right. \\
& \cdot e^{(E / R)\left(1 / T_{0}-1 / T\right)}\left(a_{0} s^{2}+b_{0} s+c_{0}\right) \operatorname{grad} C_{f}+\frac{C_{f}}{s} \\
& \left.\cdot D_{\mathrm{H}_{2} \mathrm{O}}(s) \operatorname{grad}(s)\right] .
\end{aligned}
$$

Making $k=1+\partial C_{b} / \partial C_{f}, k$ is the influence coefficient of binding of chloride ions, which is related to the type of cement. So (44) can be simplified in one dimension:

$$
\begin{aligned}
& k \frac{\partial C_{f}}{\partial t}=\frac{\partial}{\partial x}\left[D_{r, 0}^{T_{0}}\left(\frac{t_{r}}{t}\right)^{m}\right. \\
& \cdot e^{(E / R)\left(1 / T_{0}-1 / T\right)}\left(a_{0} s^{2}+b_{0} s+c_{0}\right) \frac{\partial C_{f}}{\partial x}+\frac{C_{f}}{s} \\
& \left.\cdot D_{\mathrm{H}_{2} \mathrm{O}}(s) \frac{\partial s}{\partial x}\right] .
\end{aligned}
$$

Equation (45) is the convection-diffusion model of chloride ions transport in concrete which is taken into account of the difference between dry and wet environment and the influence from concrete age, saturation, ambient temperature, and adsorption effect.

There are two variables in (45) which are chloride ions concentration $C_{f}$ and water saturation $s$. The diffusion model of water saturation of concrete can be expressed as

$$
\frac{\partial s}{\partial t}=\frac{\partial}{\partial x}\left(D_{\mathrm{H}_{2} \mathrm{O}}(s) \frac{\partial s}{\partial x}\right)
$$

Considering simultaneous Equations (45) and (46) combined with initial conditions and boundary conditions, the chloride ions concentration distribution of concrete under dry-wet cycles can be solved.

\section{Chloride Ions Transport Model in Concrete under the Combined Action of Dry-Wet Cycling and Dynamic Flexural Loading}

4.1. Establishment of Influence Coefficient of Dynamic Flexural Loading on Chloride Diffusion Coefficient and Water Diffusion Coefficient. According to the influence of dynamic flexural loading on the microcrack of concrete, the chloride diffusion coefficient of concrete under the dynamic flexural loading 
is established. So a conversion is carried out about (18). As shown in (47):

$$
D^{\prime}=D\left(1+\frac{D_{c} \rho_{e}}{D}\left(\frac{1}{\left(1-f t / 10^{(a-S) / b}\right)^{2}}-1\right)\right)
$$

This makes

$$
f_{s}=1+\frac{D_{c} \rho_{e}}{D}\left(\frac{1}{\left(1-f t / 10^{(a-S) / b}\right)^{2}}-1\right) \text {, }
$$

where $f_{s}$ is the influence coefficient of dynamic flexural loading on chloride diffusion coefficient, which represents the expansion factor of the dynamic flexural loading on the chloride ions diffusion coefficient. It is related to the initial diffusion coefficient of chloride ions.

Equation (48) characterizes the influence of microcrack propagation on chloride ions diffusion coefficient. Analogies are made between the influence coefficient of microcrack on water diffusion coefficient and influence coefficient of microcrack on chloride diffusion coefficient. The influence coefficient of dynamic flexural loading on water diffusion coefficient is

$$
f_{s}\left(\mathrm{H}_{2} \mathrm{O}\right)=1+\frac{D_{c} \rho_{e}}{D_{\mathrm{H}_{2} \mathrm{O}}}\left(\frac{1}{\left(1-f t / 10^{(a-S) / b}\right)^{2}}-1\right) .
$$

Equation (49) represents the fact that $f_{s}\left(\mathrm{H}_{2} \mathrm{O}\right)$ is related to water initial diffusion coefficient.
4.2. Diffusion Flux of Chloride Ions. Based on (24) that expresses chloride diffusion coefficient which takes concrete age, saturation, and temperature into account and (48), the effect of dynamic flexural loading on the chloride ions diffusion coefficient, the chloride ions diffusion coefficient of concrete under the combined action of dynamic flexural loading and dry- wet cycle can be expressed as

$$
\begin{aligned}
D= & D_{r, 0}^{T_{0}}\left(\frac{t_{r}}{t}\right)^{m} e^{(E / R)\left(1 / T_{0}-1 / T\right)}\left(a_{0} s^{2}+b_{0} s+c_{0}\right) \\
& \cdot\left(1+\frac{D_{c} \rho_{e}}{D_{r, 0}^{T_{0}}}\left(\frac{1}{\left(1-f t / 10^{(a-S) / b}\right)^{2}}-1\right)\right) .
\end{aligned}
$$

Therefore, the chloride ions diffusion flux into the concrete under the combined action of dynamic flexural loading and dry-wet cycle is

$$
\begin{aligned}
J_{d}= & -\Theta D_{r, 0}^{T_{0}}\left(\frac{t_{r}}{t}\right)^{m} e^{(E / R)\left(1 / T_{0}-1 / T\right)}\left(a_{0} s^{2}+b_{0} s+c_{0}\right) \\
& \cdot\left(1+\frac{D_{c} \rho_{e}}{D_{r, 0}^{T_{0}}}\left(\frac{1}{\left(1-f t / 10^{(a-S) / b}\right)^{2}}-1\right)\right) \\
& \cdot \operatorname{grad} C_{p} .
\end{aligned}
$$

4.3. Convection Flux of Chloride Ions. Based on the effect of concrete age, saturation, temperature on water diffusion coefficient (31), and the effect of dynamic flexural loading on the water diffusion coefficient (49), diffusion coefficient of water transport in concrete under the combined action of dynamic flexural loading and dry-wet cycle can be expressed as

$$
\begin{aligned}
& D_{\mathrm{H}_{2} \mathrm{O}}(s) \\
& = \begin{cases}D^{d} e^{(U / R)\left(1 / T_{0}-1 / T\right)}\left(0.3+\sqrt{\frac{13}{t}}\right)\left[\alpha+\frac{1-\alpha}{1+\left((1-s) /\left(1-s_{c}\right)\right)^{N}}\right]\left(1+\frac{D_{c} \rho_{e}}{D^{d}}\left(\frac{1}{\left(1-f t / 10^{(a-S) / b}\right)^{2}}-1\right)\right) & \text { Drying process } \\
D^{w} e^{(U / R)\left(1 / T_{0}-1 / T\right)}\left(0.3+\sqrt{\frac{13}{t}}\right) e^{n s}\left(1+\frac{D_{c} \rho_{e}}{D^{w}}\left(\frac{1}{\left(1-f t / 10^{(a-S) / b}\right)^{2}}-1\right)\right) & \text { Wetting process. }\end{cases}
\end{aligned}
$$

Therefore, the convective flux of chloride ions entering concrete under the combined action of dynamic flexural loading and dry-wet cycle is

$$
J_{c}=-C_{p} D_{\mathrm{H}_{2} \mathrm{O}}(s) \operatorname{grad} \Theta,
$$

where $D_{\mathrm{H}_{2} \mathrm{O}}(s)$ is as shown in (52).

Therefore, the total flux of chloride entering the concrete under the combined action of dynamic flexural loading and dry-wet cycle is

$$
\begin{aligned}
J= & -\Theta D_{r, 0}^{T_{0}}\left(\frac{t_{r}}{t}\right)^{m} e^{(E / R)\left(1 / T_{0}-1 / T\right)}\left(a_{0} s^{2}+b_{0} s+c_{0}\right) \\
& \cdot\left(1+\frac{D_{c} \rho_{e}}{D_{r, 0}^{T_{0}}}\left(\frac{1}{\left(1-f t / 10^{(a-S) / b}\right)^{2}}-1\right)\right) \\
& \cdot \operatorname{grad} C_{p}-C_{p} D_{\mathrm{H}_{2} \mathrm{O}}(s) \operatorname{grad} \Theta
\end{aligned}
$$

According to the law of conservation of mass of chloride ions:

$$
\frac{\partial\left(\Theta C_{p}\right)}{\partial t}=-\frac{\partial J}{\partial x}
$$

Then (54) is taken into (55), obtaining

$$
\begin{aligned}
& \frac{\partial\left(\Theta C_{p}\right)}{\partial t}=\frac{\partial}{\partial x}\left[\Theta D_{r, 0}^{T_{0}}\left(\frac{t_{r}}{t}\right)^{m}\right. \\
& \cdot e^{(E / R)\left(1 / T_{0}-1 / T\right)}\left(a_{0} s^{2}+b_{0} s+c_{0}\right) \\
& \quad\left(1+\frac{D_{c} \rho_{e}}{D_{r, 0}^{T_{0}}}\left(\frac{1}{\left(1-f t / 10^{(a-S) / b}\right)^{2}}-1\right)\right) \operatorname{grad} C_{p} \\
& \left.+C_{p} D_{\mathrm{H}_{2} \mathrm{O}}(s) \operatorname{grad} \Theta\right] .
\end{aligned}
$$


Then, chloride concentration is changed into chloride ions accounting for the mass percentage of concrete, and the adsorption effect of chloride ions is considered. Equation (56) is simplified and transformed. Then in one-dimensional direction the chloride ions transport equation is

$$
\begin{aligned}
& k \frac{\partial C_{f}}{\partial t}=\frac{\partial}{\partial x}\left[D_{r, 0}^{T_{0}}\left(\frac{t_{r}}{t}\right)^{m}\right. \\
& \cdot e^{(E / R)\left(1 / T_{0}-1 / T\right)}\left(a_{0} s^{2}+b_{0} s+c_{0}\right) \\
& \quad\left(1+\frac{D_{c} \rho_{e}}{D_{r, 0}^{T_{0}}}\left(\frac{1}{\left(1-f t / 10^{(a-S) / b}\right)^{2}}-1\right)\right) \frac{\partial C_{f}}{\partial x} \\
& \left.+\frac{C_{f}}{s} D_{\mathrm{H}_{2} \mathrm{O}}(s) \frac{\partial s}{\partial x}\right] .
\end{aligned}
$$

Equation (57) is the convection-diffusion model of chloride ions transport in concrete under the combined action of dynamic flexural loading and dry-wet cycle.

\section{Solution of Chloride Ions Transport Equation of Concrete under the Combined Action of Dynamic Flexural Loading and Dry-Wet Cycle}

The convection-diffusion model of chloride ions transport in concrete under the combined action of dynamic flexural loading and dry-wet cycle (57) contains two variables, respectively, chloride ions concentration $C_{f}$ and water saturation $s$. It cannot be solved independently. The water diffusion coefficient (46) should be introduced into (57) and the water diffusion coefficient $D_{\mathrm{H}_{2} \mathrm{O}}(s)$ is shown in (52). Considering simultaneous Equations (57) and (46), the distribution of chloride ions in concrete can be obtained by combining initial conditions and boundary conditions.

5.1. Initial Conditions. Initial saturation of concrete is $s_{0}$, and the initial chloride concentration is $C_{0}$ as follows. The amount of chloride ions invading into sample during the preparation is small and is usually regarded as 0 .

$$
\begin{gathered}
s(x \geq 0, t=0)=s_{0}, \\
C(x \geq 0, t=0)=C_{0} .
\end{gathered}
$$

5.2. Boundary Conditions. In dry-wet cycle environment, the concrete is under two stages which are drying stage and wetting stage. The boundary condition is different in different environment. When concrete is in wetting stage, the surface of concrete is in its saturation when soaked in the chloride solution. The concentration of surface pore solution is the same as that of the chloride solution as follows:

$$
\begin{gathered}
s(x=0, t)=1, \\
C(x=0, t)=c_{00},
\end{gathered}
$$

where $c_{00}$ is the percentage of chloride ions content in concrete, which can be calculated from the concentration of chloride ions and equation $C_{p}=C^{\prime} \rho_{c} / \varphi s$.

As for drying stage, assuming that the concrete surface saturation instantly becomes a constant $s_{00}$ at the beginning of drying stage, the chloride ions in the surface will not flow out with water:

$$
\begin{aligned}
& s(x=0, t)=s_{00}, \\
& D_{r, 0}^{T_{0}}\left(\frac{t_{r}}{t}\right)^{m} e^{(E / R)\left(1 / T_{0}-1 / T\right)}\left(a_{0} s^{2}+b_{0} s+c_{0}\right) \\
& \quad\left(1+\frac{D_{c} \rho_{e}}{D_{r, 0}^{T_{0}}}\left(\frac{1}{\left(1-f t / 10^{(a-S) / b}\right)^{2}}-1\right)\right) \frac{\partial C_{f}}{\partial x} \\
& +\left.\frac{C_{f}}{s} D_{\mathrm{H}_{2} \mathrm{O}}(s) \frac{\partial s}{\partial x}\right|_{x=0}=0 .
\end{aligned}
$$

Equation (61) is the boundary conditions of chloride transport equation in drying process.

As can be seen the equation of chloride ions transport in concrete under the combined action of dynamic flexural loading and dry-wet cycle is a nonlinear partial differential equation; the analytic solution of it cannot be found, so the numerical solution is appropriate to solve the problem. Firstly, the Crank-Nicolson scheme with high accuracy in the finite difference method is used to numerically discretize the model equation, the initial condition, and the boundary condition. Then the model is programmed with MATLAB; chase method is used to solve the equation.

The solution process is as follows:

(1) According to the initial conditions and boundary conditions of water transport equation, the distribution of water saturation in the concrete is calculated. Since the water transport model is a nonlinear partial differential equation, the solution is iterated to ensure the accuracy, and the saturation of the same spatial position of the adjacent time step is satisfied:

$$
\left|\frac{s_{i+1}^{j+1}-s_{i}^{j}}{s_{i}^{j}}\right| \leq \varepsilon,
$$

where $\varepsilon$ is the accuracy requirement.

(2) According to the distribution of water saturation, the initial conditions, and boundary conditions of chloride ions transport, the catching method was used to solve the concentration distribution of chloride ions in concrete.

(3) According to step (1) and step (2) the distribution of water saturation and the boundary conditions, the distribution of water saturation, and the distribution of chloride ions are solved. Step (1) and step (2) are cycled until the end of time. 
TABLE 1: Chemical composition of 42.5 ordinary Portland cement.

\begin{tabular}{lccccccc}
\hline Chemical composition & $\mathrm{SiO}_{2}$ & $\mathrm{SO}_{3}$ & $\mathrm{Fe}_{2} \mathrm{O}_{3}$ & $\mathrm{Al}_{2} \mathrm{O}_{3}$ & $\mathrm{CaO}$ & $\mathrm{MgO}$ & Loss on ignition \\
\hline Content (\%) & 21.21 & 3 & 3.46 & 5.54 & 58.69 & 0.89 & 0.88 \\
\hline
\end{tabular}

TABLE 2: Mix proportions.

\begin{tabular}{lcccc}
\hline Cement $/ \mathrm{kg}$ & Water $/ \mathrm{kg}$ & Coarse aggregate $/ \mathrm{kg}$ & Sand $/ \mathrm{kg}$ & Water reducing agent $/ \%$ \\
\hline 420 & 168 & 1250 & 588 & 0.3 \\
\hline
\end{tabular}

\section{Validation of Chloride Ions Transport Model in Concrete under Dynamic Flexural Loading and Dry-Wet Cycles}

In order to verify the rationality of the chloride ions transport model in the concrete under the combined action of the dynamic flexural loading and dry-wet cycle, indoor test was designed to simulate actual project to accelerate the ion diffusion environment, verify the model, and analyze the effect of dynamic flexural loading and dry-wet cycle on chloride ions transmission in concrete.

\subsection{Experimental Program}

6.1.1. Materials. Ordinary Portland cement was used in this research and its physical and mechanical properties are shown in Table 1. Limestone gravel was used as coarse aggregates, whose particle size was $5 \mathrm{~mm}-20 \mathrm{~mm}$ and apparent density was $2.71 \mathrm{~g} / \mathrm{cm}^{3}$. River sand was used as fine aggregates, whose fineness modulus and apparent density were 2.8 and $2660 \mathrm{~kg} / \mathrm{m}^{3}$, respectively. Polycarboxylic acid water reducing agent was used. The chloride content of water reducing agent was less than $0.01 \%$, which can be neglected. Tap water was used.

6.1.2. Mix Proportions. The water cement ratio is 0.4 of the concrete mixtures. The details of mix proportions are given in Table 2.

\subsection{Test Procedures}

6.2.1. Chloride Ions Transport Test of Concrete under Dynamic Flexural Loading and Dry-Wet Cycle. Based on literature studies [28-30], in order to simulate the actual working environment of concrete structure of road engineering and speed up the rate of chloride transport for saving test time, in this paper, the chloride ions transport test was conducted under dynamic flexural loading and dry-wet cycle, of which the two maximum stress levels were 0.6 and 0.4 and the minimum stress level was 0.1 . Drying and wetting time of the specimen were both $24 \mathrm{~h}$, which made a cycle time of $48 \mathrm{~h}$. The dynamic flexural loading frequency was 400 times/d. The concentration of $\mathrm{NaCl}$ solution was $8 \%$.

Specimens of $100 \mathrm{~mm} \times 100 \mathrm{~mm} \times 400 \mathrm{~mm}$ were prepared. After 28-day curing ages, six surfaces of specimens except two surfaces of $100 \mathrm{~mm} \times 400 \mathrm{~mm}$ were coated with anticorrosion material so that the chloride ions was onedimensional diffusion. The coated specimens were cooled for $30 \mathrm{~min}$ before soaked into water for $24 \mathrm{~h}$. A self-developed device which can assess ion transport characteristics in concrete under dynamic flexural loading and dry-wet cycle was used, and the mechanism of this device could be found in Figure 3. Firstly, the specimen was put on the test stand. Then specified concentration of chloride solution was poured into the container where the specimen was in it. Then dynamic flexural loading was applied to the specimen whose load frequency was 400 times/day. The load spectrum of dynamic flexural loading is shown in Figure 4.

6.2.2. Chloride Ions Concentration Test. The chloride ions concentration of concrete was measured in accordance with the specification (JGJ/T 322-2013). When chloride ions diffusion time reached $30 \mathrm{~d}, 60 \mathrm{~d}$, and $90 \mathrm{~d}$, the specimen was taken out from the container and air dried for $24 \mathrm{~h}$ at least. Powders from a hole which was drilled at the bending and ion diffusion surface of the specimen were used to test the chloride ions concentration.

\subsection{Comparison of Model Results with Experimental Results}

6.3.1. The Value of the Model Parameter. Model length $L$ was equal to $0.1 \mathrm{~m}$. Distance step was equal to $0.0005 \mathrm{~m}$ and time step was $1 \mathrm{~h}$. Main parameters of the calculation model during dry-wet cycle process were shown in Table 3 which referred to $\mathrm{Li}[31]$.

During dynamic flexural loading process, assuming that there was no chloride ions entering the concrete when the specimen was prepared, the initial chloride ions concentration $C_{0}=0$. The chloride concentration in porosity of the surface is the same as external environmental chloride ions concentration, so chloride concentration in porosity of the surface can be expressed as $C_{s}=C \varphi s / \rho_{c}$, where $C_{s}$ is the percentage of chloride ions content on concrete surface; $C$ is mass concentration of chloride solution, $\mathrm{kg} / \mathrm{m}^{3} ; s$ is concrete saturation, $s=1$ when the concrete was completely soaked in the solution; $\varphi$ is initial porosity of concrete, $\%$; $\rho_{c}$ is concrete density, $\mathrm{kg} / \mathrm{m}^{3}$. The diffusion coefficient of chloride in concrete $D$ is calculated according to Life-365 [32] American standard design program. Maximum diffusion coefficient from Yan [33] was adopted as diffusion coefficient of chloride ions in concrete cracks $D_{c}$. Crack area density $\rho_{e}$ was adopted from the test result of Kustermann et al. [17]. The specific values of the parameters in the model are shown in Table 4. 
TABLE 3: Parameters of the calculation model during dry-wet cycle process.

\begin{tabular}{lc}
\hline Parameter & Value \\
\hline Water diffusion coefficient during wetting process $D^{w}\left(\mathrm{~m}^{2} / \mathrm{s}\right)$ & $4.05 \times 10^{-11}$ \\
Water diffusion coefficient during drying process $D^{d}\left(\mathrm{~m}^{2} / \mathrm{s}\right)$ & $1.31 \times 10^{-10}$ \\
Initial saturation of concrete $s_{0}$ & 0.3 \\
Water saturation of concrete surface during drying process $s_{00}$ & 0.5 \\
Ambient temperature $T(\mathrm{C})$ & 25 \\
Adsorption effect factor $k$ & 0.8 \\
Saturation influence parameter $a_{0}$ & 0.0001745 \\
Saturation influence parameter $b_{0}$ & 0.01031 \\
Saturation influence parameter $c_{0}$ & 0.1820 \\
Chloride ions diffusion activation energy $E(\mathrm{~J} / \mathrm{mol})$ & 41800 \\
Water translocation activation energy $U(\mathrm{~J} / \mathrm{mol})$ & 11900 \\
\hline
\end{tabular}

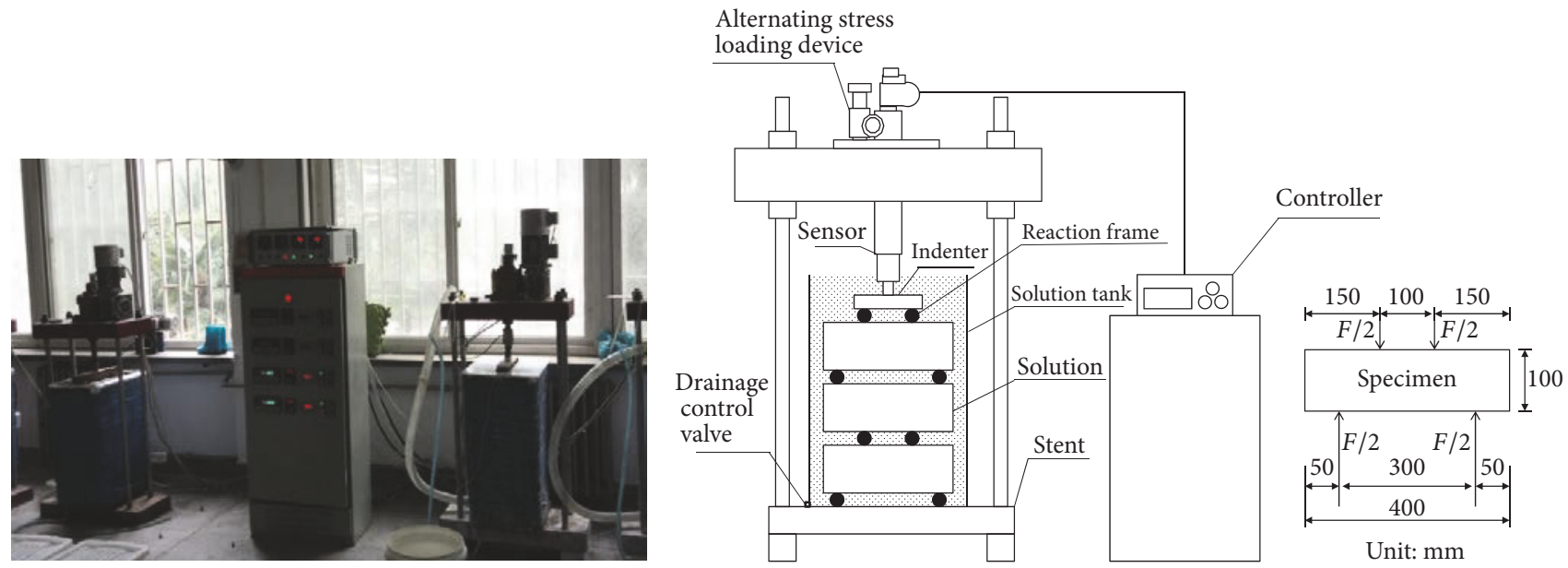

FIGURE 3: Device which can test ion transport in concrete under dynamic flexural loading and dry-wet cycle.

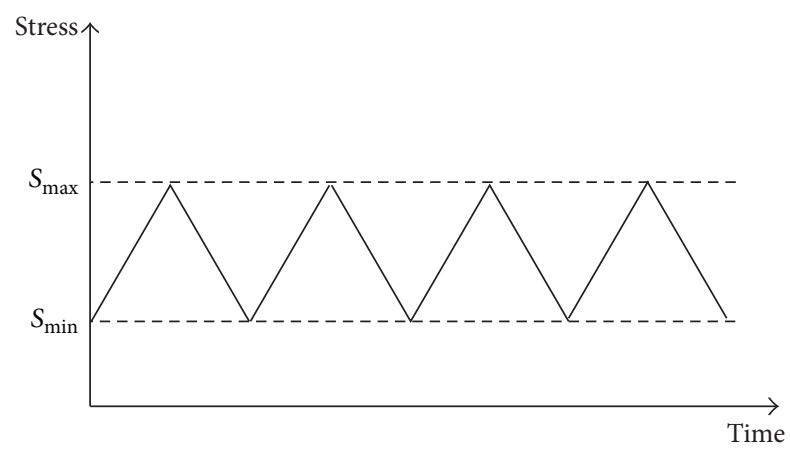

FIgURE 4: Load spectrum of dynamic flexural loading.

6.3.2. Comparative Analysis between Model Results and Experimental Results. The comparison of model results with experimental results is illustrated in Figure 5 from which it is evident that there is a good relationship between the model results and test results, especially when $x>10 \mathrm{~mm}$. The test results points are all near the calculation curve when $x>$ $10 \mathrm{~mm}$. However, when $x=2.5 \mathrm{~mm}$, the model results are quite different from the experimental results. The cause might be that when the specimen was prepared, there was a layer of cement paste on the surface. The porosity of cement paste was large. The chloride ions gathered in the pores of cement paste on the surface. On the other hand, long drying time will cause chloride redistribution on the surface of concrete. With the drying time gradually extended, moisture on the surface of concrete gradually evaporates into the air but chloride did not evaporate with water into the air, which led a small amount of chloride particles to accumulate on the surface, increasing the concentration of chloride ions on the surface. However, these chloride particles quickly dissolve in water during the wetting process, so the diffusion rate of chloride ions in concrete will not increase. It also can be seen from the results that the concentration of chloride ions was increased with time going on. The longer the concrete soaked in the chloride solution, the more the chloride ions entering the concrete. The application of dynamic flexural loading on the concrete leads the crack growing up. As the stress level increases, the crack propagation deepens which leads to the chloride ions entering concrete deeply. The cracks crack more with dynamic flexural loading time increasing, so the chloride ions entered concrete fast. 
TABLE 4: Specific values of the parameters in the model.

\begin{tabular}{lc}
\hline Parameter & Value \\
\hline Diffusion coefficient of chloride in concrete $D\left(\mathrm{~m}^{2} / \mathrm{s}\right)$ & $7.9 \times 10^{-12}$ \\
Diffusion coefficient of chloride ions in concrete cracks $D_{c}\left(\mathrm{~m}^{2} / \mathrm{s}\right)$ & $1.5 \times 10^{-9}$ \\
Initial porosity of concrete $\varphi(\%)$ & 10 \\
Water cement ratio of concrete & 0.4 \\
Initial crack area density of concrete $\rho_{e}\left(\mathrm{~mm}^{2} / \mathrm{mm}^{2}\right)$ & $61 \times 10^{-5}$ \\
Concrete density $\rho_{c}\left(\mathrm{~kg} / \mathrm{m}^{3}\right)$ & 2300 \\
Fatigue constant $a$ & 1.07 \\
Fatigue constant $b$ & 0.09 \\
Load frequency $($ times/d) & 400 \\
Maximum stress level under alternating loading $S$ & 0.6 \\
\end{tabular}

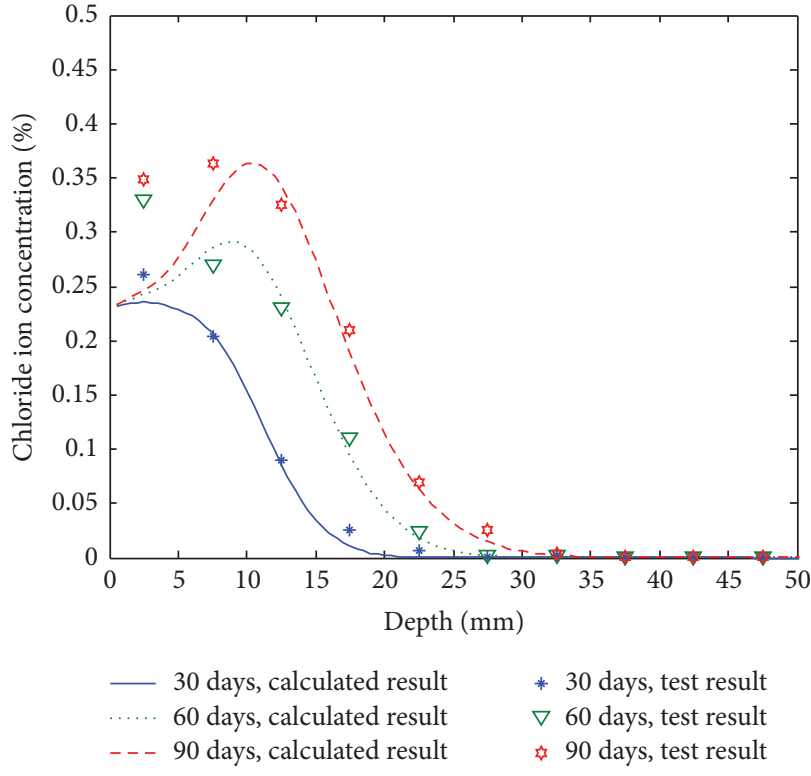

(a) The stress level is 0.4

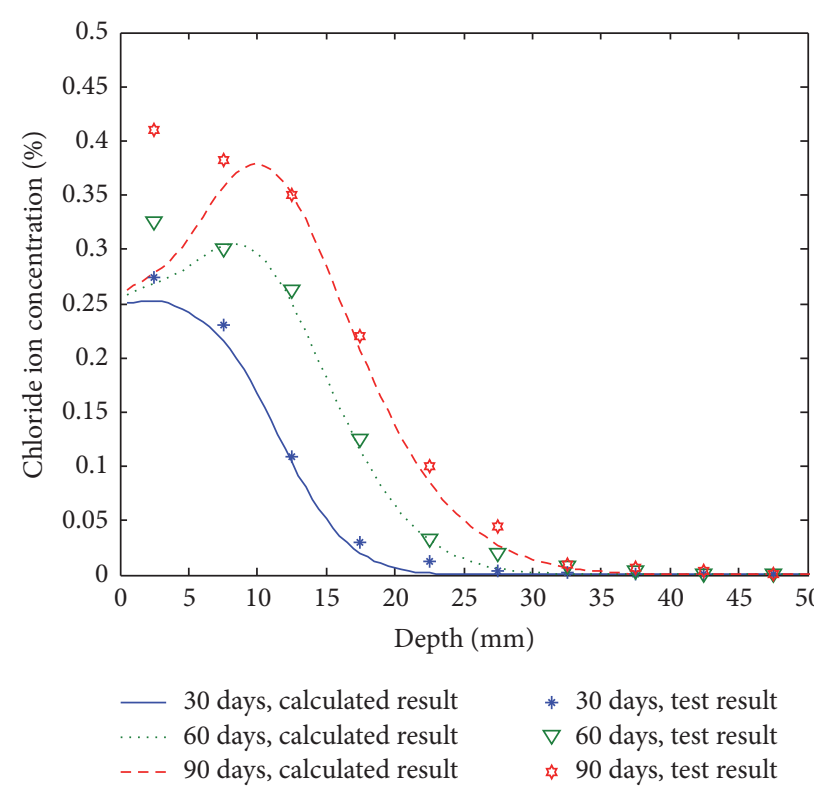

(b) The stress level is 0.6

FIgURE 5: Distribution of chloride ions concentration in concrete under dynamic flexural loading and dry-wet cycle.

\section{Conclusions}

The main objective of this study was to establish the transport model of chloride ions under the combined action of dynamic flexural loading and dry-wet cycles. Laboratory tests were conducted to verify the rationality of the model. Based on the findings of the study, the following conclusions can be drawn.

The concrete was divided into two parts: matrix and crack. Diffusion coefficient of chloride ions was characterized by initial crack area of the concrete. The damage of concrete is assumed to be the initial crack propagation. The calculation model of cumulative fatigue damage and chloride diffusion coefficient of concrete was established. The influence of dynamic flexural loading on the diffusion coefficient of chloride ions was established by introducing the stress level and the load frequency into the chloride diffusion coefficient.

Based on Fick's second law, the transmission model of chloride ions in unsaturated concrete under dynamic flexural loading was established.
The influence of concrete age, saturation, and ambient temperature on the transport of chloride ions and water in concrete and the adsorption effect of chloride ions were taken into consideration to establish the convection-diffusion model of chloride ions in concrete under dry-wet cycles. The iteration and chasing methods were used to solve the model with MATLAB programming. The results of the model are in good agreement with the experimental results.

\section{Conflicts of Interest}

There are not any conflicts of interest related to this paper.

\section{Acknowledgments}

The authors wish to thank the National Key R\&D Program of China (2017YFB0309903), the Qinghai Provincial Natural Science Foundation (2017-ZJ-764 and 2017-ZJ-763), 
Traffic Construction Project of Science and Technology of Shaanxi Province (16-16K), Traffic Construction Project of Science and Technology of Qinghai Province (2013-04), National Natural Science Foundation of China (51308062 and 51608046), and the Special Fund for Scientific Research of Central Colleges, Changan University (nos. 310831172201 and 310831163501).

\section{References}

[1] L. Wu, W. Li, and X. Yu, "Time-dependent chloride penetration in concrete in marine environments," Construction and Building Materials, vol. 152, pp. 406-413, 2017.

[2] R. B. Murugan, C. Natarajan, and S.-E. Chen, "Material development for a sustainable precast concrete block pavement," Journal of Traffic and Transportation Engineering (English Edition), vol. 3, no. 5, pp. 483-491, 2016.

[3] J. Byzyka, M. Rahman, and D. A. Chamberlain, "Thermal segregation of asphalt material in road repair," Journal of Traffic and Transportation Engineering (English Edition), vol. 4, no. 4, pp. 360-371, 2017.

[4] O. A. Hodhod and H. I. Ahmed, "Modeling the service life of slag concrete exposed to chlorides," Ain Shams Engineering Journal, vol. 5, no. 1, pp. 49-54, 2014.

[5] M. Ismail, A. Toumi, R. François, and R. Gagné, "Effect of crack opening on the local diffusion of chloride in cracked mortar samples," Cement and Concrete Research, vol. 38, no. 8-9, pp. 1106-1111, 2008.

[6] M. Boulfiza, K. Sakai, N. Banthia, and H. Yoshida, "Prediction of chloride ions ingress in uncracked and cracked concrete," ACI Materials Journal, vol. 100, no. 1, pp. 38-48, 2003.

[7] P. Liu, Z. Yu, Z. Lu, Y. Chen, and X. Liu, "Predictive convection zone depth of chloride in concrete under chloride environment," Cement and Concrete Composites, vol. 72, pp. 257-267, 2016.

[8] C. H. Wang, W. Sun, J. Y. Jiang, J. D. Han, and B. T. Ye, "Chloride ion transport performance in slag mortar under fatigue loading," Science China Technological Sciences, vol. 55, no. 5, pp. 1359-1364, 2012.

[9] C. Wang, W. Sun, J. Jing, J. Han, and H. Rong, "The transport properties of concrete under the simultaneous coupling of fatigue load and environment factors," Journal of Wuhan University of Technology-Mater. Sci. Ed., vol. 27, no. 1, pp. 181186, 2012.

[10] Y. Ren, Q. Huang, Q. Y. Liu, J. Z. Sun, and X. L. Liu, "Chloride ion diffusion of structural concrete under the coupled effect of bending fatigue load and chloride," Materials Research Innovations, vol. 19, pp. S1181-S1184, 2015.

[11] S.-P. Yin, M.-W. Na, Y.-L. Yu, and J. Wu, "Research on the flexural performance of RC beams strengthened with TRC under the coupling action of load and marine environment," Construction and Building Materials, vol. 132, pp. 251-261, 2017.

[12] H. Ye, X. Jin, C. Fu, N. Jin, Y. Xu, and T. Huang, "Chloride penetration in concrete exposed to cyclic drying-wetting and carbonation," Construction and Building Materials, vol. 112, pp. 457-463, 2016.

[13] M. Isteita and Y. Xi, "The effect of temperature variation on chloride penetration in concrete," Construction and Building Materials, vol. 156, pp. 73-82, 2017.
[14] J. Wu, H. Li, Z. Wang, and J. Liu, "Transport model of chloride ions in concrete under loads and drying-wetting cycles," Construction and Building Materials, vol. 112, pp. 733-738, 2016.

[15] J. Xu and F. Li, "A meso-scale model for analyzing the chloride diffusion of concrete subjected to external stress," Construction and Building Materials, vol. 130, pp. 11-21, 2017.

[16] L. Jiang, C. Li, C. Zhu, Z. Song, and H. Chu, "The effect of tensile fatigue on chloride ion diffusion in concrete," Construction and Building Materials, vol. 151, pp. 119-126, 2017.

[17] A. Kustermann, K. C. Thienel, and M. Keuser, "Influence of curing methods on the formation of microcracks in high-strength concrete," in Proceedings of the 7th International Symposium on the Utilization of High-Strength/High-Performance Concrete, pp. 1282-1294, Washington, DC, USA, June 2005.

[18] S. G. Li, G. X. Chen, G. J. Ji et al., "Quantitative analysis of initialm icrecrack in high strength concrete by DIP technique," Concrete, no. 5, pp. 6-8, 2013 (Chinese).

[19] C. Peng, Fatigue damage and life prediction of prefabricated crack concrete [dissertation], Wuhan University of Technology, Wuhan, China, 2013, (in Chinese).

[20] J.-Y. Jiang, W. Sun, Z.-Q. Jin, and C.-H. Wang, "Service life prediction of structural concrete under coupled interactions of fatigue loading and carbonation factor," Journal of Building Materials, vol. 13, no. 3, pp. 304-309, 2010.

[21] P. S. Mangat and B. T. Molloy, "Prediction of long term chloride concentration in concrete," Materials and Structures, vol. 27, no. 6, pp. 338-346, 1994.

[22] C. Dura, General guidelines for durability design and redesign, Probabilistic Performance Based Durability Design of Concrete Structure, 2000.

[23] A. T. C. Guimarães, M. A. Climent, G. D. Vera, F. J. Vicente, F. T. Rodrigues, and C. Andrade, "Determination of chloride diffusivity through partially saturated Portland cement concrete by a simplified procedure," Construction and Building Materials, vol. 25, no. 2, pp. 785-790, 2011.

[24] G. de Vera, M. A. Climent, E. Viqueira, C. Antón, and C. Andrade, "A test method for measuring chloride diffusion coefficients through partially saturated concrete. Part II: the instantaneous plane source diffusion case with chloride binding consideration," Cement and Concrete Research, vol. 37, no. 5, pp. 714-724, 2007.

[25] A. V. Saetta, R. V. Scotta, and R. V. Vitaliani, "Analysis of chloride diffusion into partially saturated concrete," ACI Materials Journal, vol. 90, no. 5, pp. 441-451, 1993.

[26] W. Jin, Durability Theory and Design Method of Concrete Structure under Chloride Environment, Science Press, Beijing, China, 2011.

[27] G. Lin, Y. H. Liu, and Z. H. Xiang, "Numerical modeling for predicting service life of reinforced concrete structures exposed to chloride environments," Cement and Concrete Composites, vol. 32, no. 8, pp. 571-579, 2010.

[28] Y.-T. Chang, F. Tian, and Z. Zhang, "Dynamic fatigue loading effects on the impermeability of different parts of concrete pavement," Journal of Wuhan University of Technology, vol. 36, no. 11, pp. 53-57, 2014.

[29] L. W. Su, Z. Q. Ying, P. G. Liu et al., "On load level of concrete structure," Port and Waterway Engineering, no. 1, pp. 75-79, 2015.

[30] Q. Z. Zhang, Q. H. Huang, W. P. Zhang et al., "Study on accelerated chloride penetration testing methods for concrete in tidal zone," Structural Engineers, vol. 26, no. 3, pp. 145-153, 2010. 
[31] C. Q. Li, Study on water and ionic transport processes in cover concrete under drying-wetting cycles [dissertation], Tsinghua University, Beijing, China, 2009, (in Chinese).

[32] Life-365, Computer program for predicting the service life and life cycle costs of RC exposed to chloride, Version 2.0, 2008.

[33] Y. D. Yan, Transportation of chloride ions in damaged and cracked concrete and its action [dissertation], Zhejiang University, Hangzhou, China, 2011, (in Chinese). 


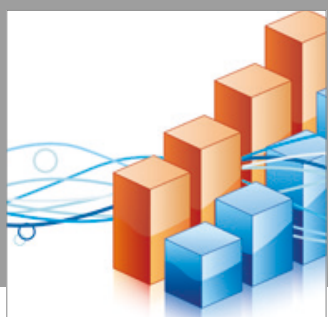

Advances in

Operations Research

vatersals

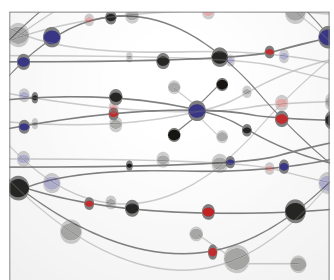

\section{The Scientific} World Journal
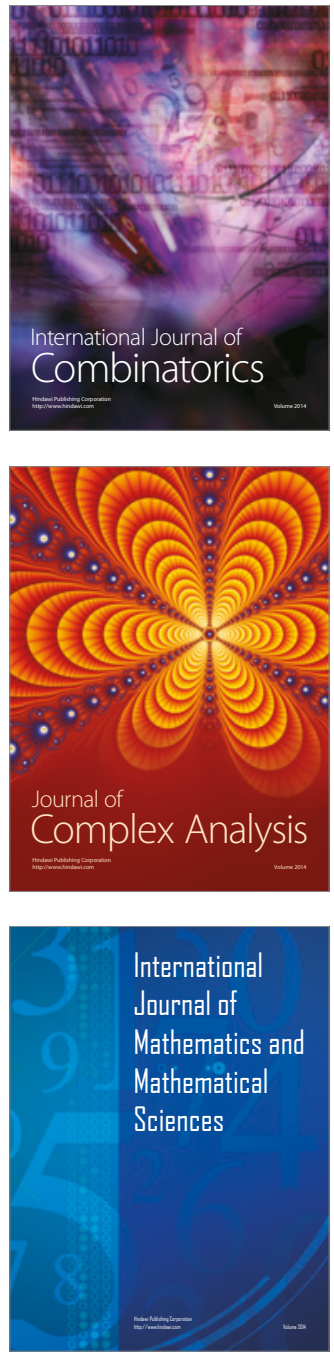
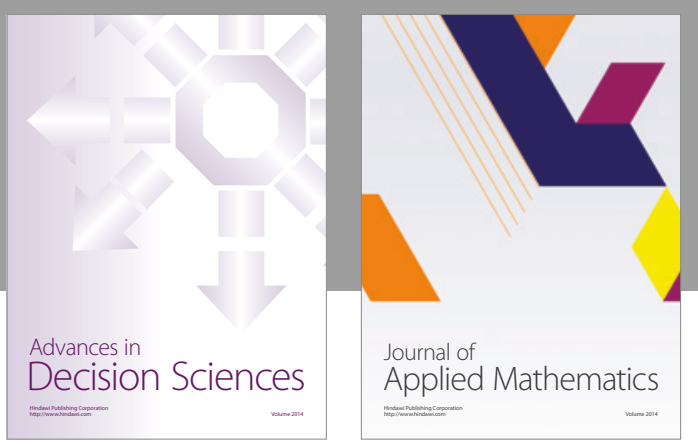

Algebra

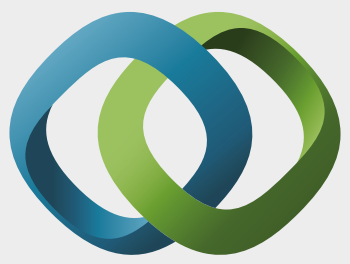

\section{Hindawi}

Submit your manuscripts at

https://www.hindawi.com
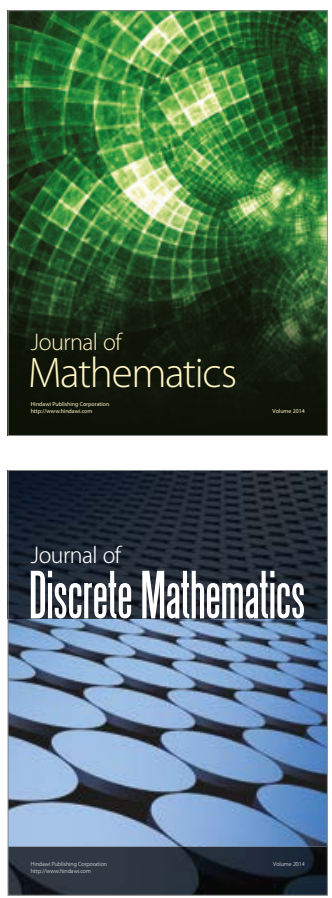

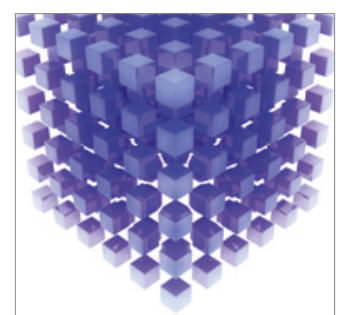

Mathematical Problems in Engineering
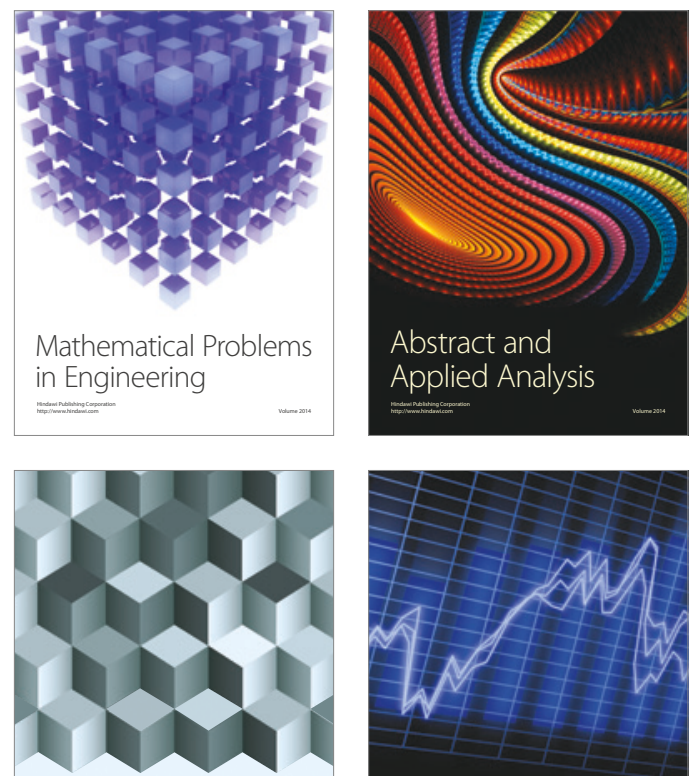

Journal of

Function Spaces

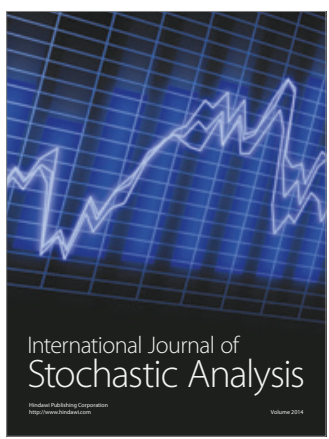

Probability and Statistics
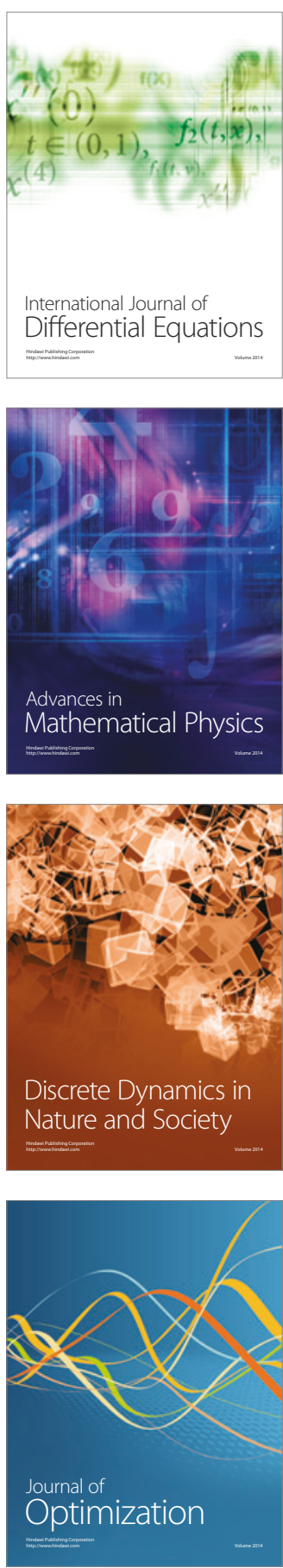